\title{
La importancia del reconocimiento legal de la consulta previa a comunidades campesinas en el Perú
}

\section{The Relevance of the Legal Acknowledgement of the Prior Consultation for Farmer Communities in Peru}

Gilberto Vladimir Guerrero Carranza;* José Ronald Vásquez Sánchez**

http://dx.doi.org/10.21503/lex.v16i22.1648

* Abogado por la Universidad Privada César Vallejo, sede Lima Este. Cursa la Maestría en Derecho con mención en Derecho de la Empresa, en la Universidad Nacional Mayor de San Marcos.

Correo electrónico: gvgc3101@gmail.com

** Licenciado en Educación y abogado. Segunda especialidad en Derecho Ambiental y Recursos Naturales por la Pontificia Universidad Católica del Perú. Magíster en Historia de la Filosofía, por la Universidad Nacional Mayor de San Marcos. Egresado del doctorado en Ciencias Ambientales de la Universidad Nacional Mayor de San Marcos. Docente universitario de pregrado y posgrado, Academia de la Magistratura.

Correo electrónico: jose.vasquez@uarm.pe

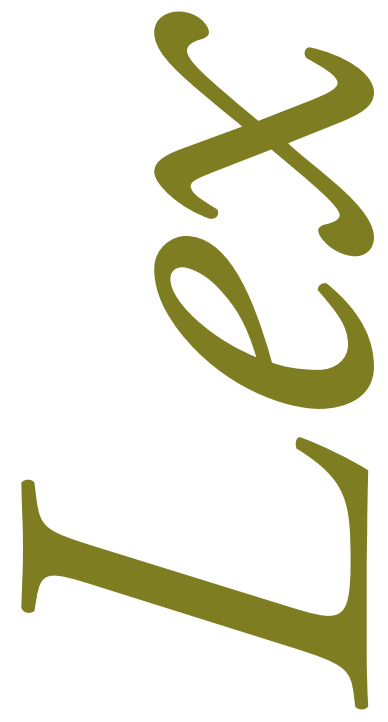




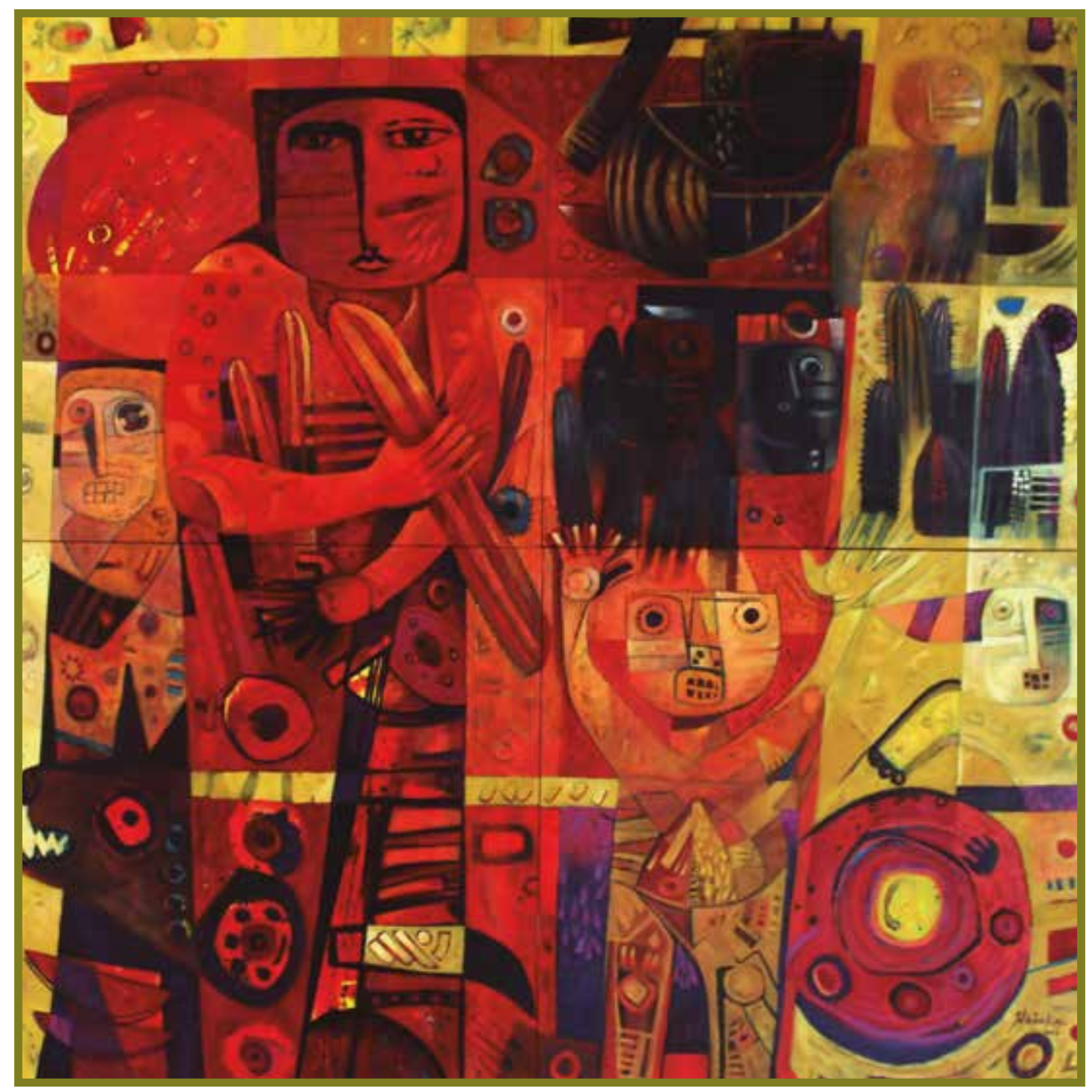

El encanto del Chamán. Pintura. Juan Carlos Ñañake. 


\section{RESUMEN}

El artículo 1 del Convenio 169 de la OIT (Organización Internacional del Trabajo, 1989) institucionaliza el derecho de consulta previa enfocado en garantizar a los pueblos indígenas que tengan una participación más interviniente cada vez que el Estado tome decisiones de carácter político, social y económico en los procesos que puedan afectar el entorno cultural de las mismas. La ley $\mathrm{N}^{\circ} 29785$ (Congreso de la República, 2011) promulgada el 6 de septiembre de 2011 regula el derecho a la consulta previa de los pueblos indígenas u originarios del país, la misma que no regula a las comunidades campesinas como sujetos de la presente norma. Esto es, en principio una acción muy reprochable debido a que actualmente se viene realizando actividades de exploración y explotación en territorio campesino sin tener en cuenta la afectación al derecho constitucional a vivir y desarrollarse en un ambiente sano y equilibrado para el desarrollo de la vida. La propuesta planteada es que el derecho a la consulta previa debe aplicarse tanto a comunidades nativas como a las comunidades campesinas, porque la mera realización de una actividad minera afecta derechos fundamentales y el entorno cultural, con la finalidad de prevenir posibles conflictos sociales.

Palabras clave: derecho a la consulta previa, comunidades indigenas y campesinas, Estado.

\section{ABSTRACT}

Article 1 of the ILO Convention 169 (International Labor Organization, 1989),institutionalizes the right of prior consultation focused on guaranteeing indigenous people right to a greater participation on the Government decision making on political, social and economic grounds regarding processes that may affect their cultural environment. The Law $N^{\circ} 19785$ (Parliament, 2011) promulgated on September 6, 2011, regulates the Right to Prior Consultation of the Indigenous or Native Peoples, which does not regulate the farmer communities as subjects of the said. That is, a highly reprehensible omission, due to the fact that exploration and operation activities are carried out within farmers' territory disregarding their constitutional rights to live and develop in a healthy and balanced environment. This work proposes that the Prior Consultation should be applied both to indigenous communities and to farmer communities as the sole installation of mining activities affects fundamental rights and cultural environment in order to prevent potential social conflicts.

Key words: right to prior consultation, indigenous and farmer communities, Government. 


\section{INTRODUCCIÓN}

Los incentivos estatales de los últimos ańos para la inversión minera en nuestro país ha generado, en gran parte, mucha expectativa económica debido a que nuestro país es uno de los exportadores de minerales con mayor expectativa de toda América Latina. Ello ha provocado la explotación de nuestros recursos naturales en diferentes zonas del país, la cual ha generado amenazas a los pueblos indígenas y comunidades campesinas por el despojo de sus tierras. En ese sentido, es que el derecho a la consulta previa debe ser libre y directo para que los indígenas y campesinos tomen decisiones que favorezcan a toda la comunidad, ya que la aplicación de tal derecho constituye una exigencia constitucional, como lo señala el Convenio $\mathrm{N}^{\circ} 169$ de la OIT (Organización Internacional del Trabajo, 1989), desde su entrada en vigencia.

Hoy, la Ley de La Consulta Previa N²9785 (Congreso de la República. 2011) no está cumpliendo con los estándares por los cuales se promulgó; es por ello que ha provocado un completo desengaño para todas aquellas comunidades nativas y campesinas en nuestro país. Lo más resaltante de este hecho es que los funcionarios encargados de realizar y ejecutar dichas políticas de negociación lo han manejado de la peor manera, con lo cual han traído mayor desconfianza de los pueblos indígenas y campesinos hacia el Estado.

Lo que se pretende, finalmente, es analizar el derecho a la consulta previa y su aplicación actual en nuestro país. En definitiva, lo que se pretende es el reconocimiento y regulación del citado derecho y su aplicación en comunidades campesinas. Esto es, debe reconocerse tal derecho no solamente a indígenas sino también a campesinos, ya que en ambos se vulnera sus derechos fundamentales cada vez que el Estado toma decisiones administrativas que afectan su entorno cultural.

\section{CONSIDERACIONES GENERALES DEL DERECHO A LA CONSULTA PREVIA}

El Convenio 169 de la OIT (Organización Internacional del Trabajo, 1989) señala que: 
Los Gobiernos deberán consultar a los pueblos interesados, mediante procedimientos apropiados y en particular a través de sus instituciones representativas, cada vez que se prevean medidas legislativas o administrativas susceptibles de afectarles directamente. (Art. 6 inc. 1 literal a).

Las consultas llevadas a cabo en aplicación de este Convenio deberán efectuarse de buena fe y de una manera apropiada a las circunstancias, con la finalidad de llegar a un acuerdo o lograr el consentimiento acerca de las medidas propuestas (Art. 6 inc. 2.). ${ }^{1}$

Este convenio en la actualidad es el referente legislativo vigente a nivel internacional. Recalca que los Estados miembros deben aplicar procedimientos comunicativos y de consulta cada vez que este se atribuya la propiedad de los recursos minerales encontrados en el subsuelo con la finalidad de no afectar los intereses y derechos de los pueblos. Asimismo, el Estado debe tomar en cuenta las consecuencias beneficiosas o catastróficas que acarrearía este tipo de actividades y de verse afectado el Estado debe primar el derecho de los pueblos ante cualquier actividad extractiva.

En ese sentido, podemos argumentar que el derecho a la consulta ha ido evolucionando y, más aún, ha generado cambios en la estructura de los pueblos indígenas en gran parte del mundo. La meta de dicho convenio es reconocer las esperanzas de esos pueblos a asumir el control propio, esto es, la toma de decisiones respecto a su forma y estilo de vida, desarrollo económico y, lo más importante, el fortalecimiento de su identidad étnica y cultural.

En ese orden de ideas, el Estado es el único responsable de desarrollar mecanismos de protección a los derechos que cuentan los pueblos indígenas, además del respeto a su dignidad e integridad, las mismas que deben ser garantizadas cada vez que el Estado tome decisiones legislativas y administrativas que puedan afectar su espacio natural.

También según el Convenio 169 de la OIT (Organización Internacional del Trabajo, 1989):

Los pueblos interesados deberán tener el derecho de decidir sus propias prioridades en lo que atañe el proceso de desarrollo, en la medida en que este afecte a sus vidas, creencias, instituciones y bienestar espiritual y a las tierras que ocupan o utilizan de alguna manera, y de controlar, en la medida de lo posible, su propio desarrollo económico, social y cultural. Además, dichos pueblos deberán participar en la formulación, aplicación y evaluación de los planes y programas de desarrollo nacional y regional susceptibles de afectarles directamente (Art. 7 inc. 1.). ${ }^{2}$

1 Convenio No 169 de la OIT. Ver Declaración de las Naciones Unidas sobre los Derechos de los Pueblos Indígenas (Oficina Regional para América Latina y el Caribe, 2007), acceso el 28 de agosto de 2018, http://www.ilo.org/wcmsp5/groups/ public/---americas/---ro-lima/documents/publication/wcms_345065.pdf

2 Convenio No 169 de la OIT. Ver Declaración de las Naciones Unidas sobre... 
Queda claro que la razón de ser de este convenio es priorizar los derechos de las comunidades indígenas, la consulta previa es un mecanismo de defensa utilizado por el Gobierno y las instituciones que representan a dichas comunidades. Se establece que cuando las decisiones administrativas y legislativas repercuten en su forma de vida, creencias y bienestar espiritual, el Estado deberá primar la cultura de los pueblos indígenas y en lo posible hacerlos partícipes de las decisiones para alcanzar su propio desarrollo, sin por ello tener que afectar sus derechos colectivos.

Por otro lado, es importante señalar que tal derecho de decisión recae exclusivamente en la consulta. Es decir, el Gobierno debe establecer el reglamento y los procedimientos para articular de la mejor manera el proceso de consulta. Esto es, definir las etapas, plazos y la manera en que dichas consultas se llevarán a cabo respetando las tradiciones y costumbres de los pueblos indígenas.

De acuerdo al Art. 16 del Convenio 169 de la OIT, en donde el Estado haya incursionado sin respetar el derecho de los pueblos indígenas a ser consultados debidamente, y que tales acciones hubiesen generado afectaciones irreversibles a espacios indígenas, en principio, el Estado debe tener en cuenta el interés superior de la nación y de toda la población que pudo verse afectada. En tal sentido, lo que deberá hacer el Estado, excepcionalmente, es la reubicación y traslado de esos pueblos, quienes solo deberán efectuarse con su consentimiento, forma libre y con pleno conocimiento de la causa.

No obstante, el Estado peruano actualmente sigue otorgando concesiones mineras, petroleras, etc., en diferentes territorios indígenas y campesinos sin tener en cuenta el derecho a la consulta, afectando de manera directa los derechos de estos comuneros a desarrollarse en un ambiente sano, adecuado y libre de contaminación. Es por ello que a raíz de estos hechos se han generado una serie de conflictos socioambientales debido a que nuestro país actualmente no viene aplicando el derecho a la consulta previa, como lo señala el Convenio $\mathrm{N}^{\circ} 169$ de la OIT (Organización Internacional del Trabajo, 1989), de la cual forma parte nuestro país.

Por otro lado, en la Declaración de las Naciones Unidas sobre los Derechos de los Pueblos Indígenas se indica que:

Los pueblos indígenas tienen derecho a la libre determinación. En virtud de ese derecho determinan libremente su condición política y persiguen libremente su desarrollo económico, social y cultural (Art. 3).

Los pueblos indígenas, en ejercicio de su derecho a la libre determinación, tienen derecho a la autonomía o al autogobierno en las cuestiones relacionadas con sus asuntos internos y locales, así como a disponer de medios para financiar sus funciones autónomas (Art. 4). ${ }^{3}$

3 Declaración de las Naciones Unidas sobre los... 
Esta declaración aprobada en el año 2007 por la Organización de las Naciones Unidas $(\mathrm{ONU})$ es un instrumento que vincula jurídicamente a nuestro país porque es parte de ella. Es decir, la protección de la consulta previa y de los derechos de los pueblos indígenas se realiza de forma directa, con el libre consentimiento previo e informado. Al respecto, los artículos (Art. 3 y Art. 4 de la Declaración de las Naciones Unidas) hacen mención a una extensa defensa de derechos indígenas y al mismo tiempo la forma de resolución de conflictos que puedan emerger entre los pueblos indígenas y los Estados por causas de extracción o exploración de recursos naturales dentro del territorio indígena.

En definitiva, los diferentes tratados y convenios internacionales se caracterizan por su notable aportación a la protección de los derechos de los pueblos indígenas y por la existencia de organismos internacionales de velar ante afectaciones a derechos humanos. Además, el tema de consulta previa actualmente traspasó fronteras y hoy es considerado un asunto especializado dentro del ámbito jurídico, político y social.

\section{ANÁLISIS DEL TRIBUNAL CONSTITUCIONAL SOBRE EL DERECHO A LA CONSULTA PREVIA EN EL PERÚ}

El Tribunal Constitucional en más de una oportunidad se ha pronunciado en torno a la obligación que tiene el Estado peruano de obtener el consentimiento para llevar a cabo el proceso consultivo. Ratifica el carácter constitucional del Convenio 169 de la OIT (Organización Internacional del Trabajo, 1989), señalando que los tratados internacionales sobre derechos humanos no solo conforman nuestro ordenamiento jurídico, sino que también ostentan rango constitucional (STC No0025-2005-PI/TC). ${ }^{4}$

En ese mismo sentido, en virtud de lo señalado en el artículo V del Título Preliminar de Código Procesal Constitucional, el mismo que establece que todos los derechos constitucionales protegidos deben interpretarse de conformidad con la Declaración Universal de los Derechos Humanos así como con las decisiones adoptadas por los tribunales internacionales sobre derechos humanos, de los cuales el Perú es parte (Congreso de la República Ley $\mathrm{N}^{\circ}$ 28237, pág. 2). ${ }^{5}$

La sentencia No 0022-2009-PI/TC ${ }^{6}$ es un referente significativo sobre pueblos indígenas y el derecho de consulta y consentimiento. En dicha sentencia se ratifica tal derecho fundamental, basado en principios rectores, cuya finalidad es preservar la integridad sociocultural,

\footnotetext{
4 Tribunal Constitucional, Jurisprudencia, 2005, acceso el 15 de setiembre, http://www.tc.gob.pe/jurisprudencia/2006/00025-2005-AI\%2000026-2005-AI\%20Admisibilidad.html

5 Congreso de la República, Ley No 28237, acceso el 17 de setiembre de 2018, https://www.tc.gob.pe/tc/private/adjuntos/ institucional/normatividad/codigo_procesal.pdf

6 Tribunal Constitucional, Jurisprudencia, 2009, acceso el 18 de setiembre de 2018, https://www.tc.gob.pe/jurisprudencia/2010/00022-2009-AI.html
} 
económica y étnica de las comunidades. Lo resaltante de esta sentencia es que el derecho a la consulta se fundamenta en que los pueblos indígenas poseen la libertad de establecer cuáles son sus prioridades de desarrollo para llegar a un acuerdo. Además, establece los mecanismos y procedimientos que garanticen la aplicación de ese derecho de tal manera que conceda a los pueblos indígenas la oportunidad de tomar decisiones que afecten su territorio y espacio cultural.

Otra sentencia cuyos fundamentos versan sobre derechos de los pueblos indígenas es la sentencia No 1126-2011-HC/TC ${ }^{7}$ (comunidad nativa Tres Islas - Madre de Dios). Con ella se generó un precedente sobre la autonomía y el control de sus territorios de los pueblos indígenas y, a la vez, es un antecedente explícito para el Estado de que dichos pueblos tienen pleno derecho sobre sus tierras, propiedad y autonomía de la comunidad.

El derecho constitucional a la consulta previa señalada en la citada sentencia recordó a todas las autoridades nacionales, regionales y locales que antes de tomar alguna medida en donde se pueda afectar el desarrollo de la vida de las poblaciones indígenas se debe consultar a las mismas con la finalidad de garantizar sus derechos constitucionales.

Nuestra jurisprudencia constitucional en materia de derechos de pueblos indígenas es muy amplia, en el sentido de que su pronunciamiento se enfocó principalmente en la obligación que tiene el Estado peruano de reconocer el derecho constitucional a la consulta previa. En este sentido, queda claro que el reconocimiento de tal derecho está siento interpretado por el Tribunal Constitucional, en concordancia con el Convenio 169 de la OIT, así como con las Declaración de las Naciones Unidad sobre los derechos de los pueblos indígenas y demás tratados internaciones de la cual forma parte nuestro país.

\section{EL DERECHO A LA CONSULTA PREVIA}

Antes de la promulgación de la Ley Nº 29785 (Congreso de la República, 2011), se generó un espacio de crítica en el Congreso de la República. Al respecto, el Doctor Javier Valle Riestra ${ }^{8}$ preguntó: “¿Por qué se armaría todo un aparato gigantesco, burocrático, dinámico, agitador de las masas, si en definitiva las comunidades no tendrán derecho a veto? Esto significa que a pesar de que los pueblos no se encuentren de acuerdo con lo propuesto por el Gobierno, ellos no tienen la facultad de oponerse, $y$, en definitiva, esto es irracional.

En el primer periodo del Gobierno del expresidente Ollanta Humala, el 6 de setiembre de 2011 se promulgó la Ley N ${ }^{\circ} 29785,{ }^{9}$ Ley de Derecho a la Consulta Previa a los pueblos Indí-

7 Tribunal Constitucional, Jurisprudencia, 2011, acceso el 18 de setiembre de 2018, http://www.tc.gob.pe/jurisprudencia/2012/01126-2011-HC.html

8 J. Valle, “Comisión de Constitución elaborará tercer dictamen sobre Ley de Consulta”, 2010, https://www.servindi.org/ actualidad/25629

9 Congreso de la República (2011), "Ley de Derecho a la Consulta Previa a los Pueblos Indígenas u Originarios”, acceso el 18 
genas u Originarios, la misma que fue reglamentada el 3 de marzo de 2012 por Decreto Supremo $\mathrm{N}^{\circ}$ 001-2012-MC, ${ }^{10}$ señalando taxativamente a quiénes se considera pueblos indígenas en nuestro país y cuál sería la manera para que estos puedan ejercer tal derecho. Con dicha Ley, el Estado peruano oficializó la protección de los derechos colectivos de los pueblos indígenas.

Respecto al objeto de la Ley No 29785 (Congreso de la República. 2011), indica que:

La presente Ley desarrolla el contenido, los principios y el procedimiento del derecho a la consulta previa a los pueblos indígenas $\mathrm{u}$ originarios respecto a las medidas legislativas o administrativas que les afecten directamente. Se interpreta de conformidad con las obligaciones establecidas en el Convenio 169 de la Organización Internacional del Trabajo (OIT), ratificado por el Estado peruano mediante la Resolución Legislativa 26253 (Art.1).

Lo detallado en los capítulos anteriores deja claro que el derecho de consulta previa tiene rango constitucional, por ende, debe ser interpretado respetando todos los parámetros constitucionales que señala nuestra norma suprema. Esto es, ceñirse a los tratados y convenios internacionales ratificados por nuestro país. Además, este derecho, en principio, tiene que ser garantizado por el Estado mismo y, a la vez, este tiene que utilizar las herramientas necesarias (etapas y procedimientos) para llevar a cabo el proceso de consulta en los pueblos indígenas.

En este escenario, debemos tener en cuenta que el derecho a la consulta adquiere mayor notoriedad por los hechos sucedidos en la provincia de Bagua, en Amazonas. Aquel conflicto se suscitó debido a que el Estado había emitido una serie de derechos legislativos que en principio fueron considerados como abusivos por los indígenas, ya que afectaban a sus derechos constitucionales, particularmente a ser consultados. De allí en adelante se originó una grave situación problemática entre el Estado y los pueblos indígenas debido a la falta de diálogo e inclusión de estos pueblos en la toma de decisiones estatales.

Al respecto, la Ley N² 29785 (Congreso de la República, 2011) define a la consulta previa como:

El derecho de los pueblos indígenas u originarios a ser consultados de forma previa sobre las medidas legislativas o administrativas que afecten directamente sus derechos colectivos, sobre su existencia física, identidad cultural, calidad de vida o desarrollo. También corresponde efectuar la consulta respecto a los planes, programas y proyectos de desarrollo nacional y regional que afecten directamente estos derechos.

La consulta a la que hace referencia la presente Ley es implementada de forma obligatoria solo por el Estado (Art. 2). ${ }^{11}$

de setiembre de 2018, http://www.drelp.gob.pe/DIGEIBIRA/COMUNICADOS/Ley\%20N\%C2\%BA\%2029785.pdf

10 Decreto Supremo, 2012, http://consultaprevia.cultura.gob.pe/wp-content/uploads/2014/11/Reglamento-de-la-Ley-N--29785-Decreto-Supremo-N---001-2012-MC.pdf

11 Congreso de la República (2011), "Ley de Derecho a la Consulta Previa... 
El proceso de consulta para llevarse a cabo debe versar exclusivamente sobre afectaciones a derechos colectivos como la identidad, cultura, calidad de vida o desarrollo. Tales derechos han sido previstos y clasificados como derechos constitucionales protegidos por el mismo Tribunal Constitucional. No debemos dejar de mencionar que el artículo antes citado merece una crítica debido a que supone que el proceso de consulta no debe realizarse cuando se traten de derechos individuales de los integrantes de los pueblos indígenas, porque el artículo 6 del Convenio 169 de la OIT (Organización Internacional del Trabajo, 1989) hace tremenda distinción, lo que exige es que se afecten principalmente los pueblos indígenas.

En conclusión, el Estado es el único obligado a implementar el proceso de consulta previa y lo hace a través de organismos descentralizados como puede ser el Congreso de la República, los Ministerios, Gobiernos Regionales y Municipalidades, etc. Establecido esto, el rol de las empresas debe ceñirse en la negociación con los pueblos y el acceso a su espacio territorial. Además, deben, las empresas, realizar actividades de responsabilidad social para crear un ambiente de diálogo y relaciones con los indígenas.

\section{LAS COMUNIDADES CAMPESINAS EN EL PERÚ}

En primer lugar, es necesario realizar la diferenciación en cuanto a la temática de comunidades campesinas y nativas, toda vez que poseen características particulares y esa diferenciación nos permitirá contextualizar mejor, para que así podamos analizar lo señalado taxativamente en el artículo 89 de la Constitución Política del Perú (Congreso de la República del Perú, 1993), artículo que contiene una serie de derechos que identifican a dichas organizaciones culturales. Además, es necesario e importante su estudio, debido a que estas comunidades tienen una participación activa en la estructura del Estado.

La Ley General de Comunidades Campesinas Ley No 24656 (Congreso de la República, 1987) señala que:

Las Comunidades Campesinas son organizaciones de interés público, con existencia legal y personería jurídica, integrados por familias que habitan y controlan determinados territorios, ligadas por vínculos ancestrales, sociales, económicos y culturales, expresados en la propiedad comunal de la tierra, el trabajo comunal, la ayuda mutua, el gobierno democrático y el desarrollo de actividades multisectoriales, cuyos fines se orientan a la realización plena de sus miembros y del país (Artículo $2^{\circ}$ ).

Por su parte, el Decreto Ley No 22175 Ley de Comunidades Nativas y de Desarrollo Agrario de la Selva y de Ceja de Selva (Congreso de la República, 1978) indica:

Las Comunidades Nativas tienen origen en los grupos tribales de la Selva y Cejas de Selva y están constituidas por conjuntos de familias vinculadas por los siguientes elementos principales: idioma o dialecto, caracteres culturales y sociales, tenencia y usufructo común y permanente de un mismo territorio, con asentamiento nucleado o disperso (Artículo $8^{\circ}$ ). 
Visto así, las comunidades campesinas y nativas poseen características diferentes en cuanto a la zona donde se encuentran ubicadas. Las primeras, por lo general, se encuentran en zonas rulares y altoandinas del Perú, y las segundas se ubican en zonas de la Amazonía nacional y tienen su propia autonomía. Es decir, su estructura social y política están basadas en la familia y su entorno cultural. La diferencia es que en las comunidades campesinas cada comunero posee una parcela de tierra para practicar la agricultura, a diferencia de las comunidades nativas en que estas aprovechan los bosques y ríos para subsistir y buscar alimentos. En definitiva, ambas actividades son realizadas para satisfacer necesidades primarias y de supervivencia.

Por otro lado, estas comunidades históricamente han adquirido un espacio dentro de nuestro país y el rol que cumplen cada una de ellas es importante en la medida que brindan un legado cultural e histórico representativo. Por ende, el Estado les otorga personería jurídica propia para el mejor manejo de su territorio (parcelas, tierras, bosques, etc.) y la existencia legal para que regulen y formen sus propios órganos representativos.

Peña define a las comunidades campesinas:

Como unidades que combinan funciones de regulación económica y social sobre sus integrantes, que comparten una propiedad y que interactúan como colectividad ante la sociedad mayor (p. 26). ${ }^{12}$

Las comunidades campesinas son organizaciones administrativas y culturales, cuya finalidad es la búsqueda del bien común de todos sus comuneros. Esto es, comparten sus territorios y se muestran como una sola unidad ante la sociedad. La búsqueda del bienestar general es de manera colectiva, mas no individual. Su papel es protagónico, pese a que el Gobierno central no brinda todas las facilidades de acceso a los servicios públicos y más aún, teniendo en consideración que estas representan la mayor parte del territorio nacional.

Por todo lo dicho líneas arriba, creemos que el derecho de consulta previa también debe aplicarse a las comunidades campesinas, porque en las decisiones (administrativas y legislativas) tomadas por el Estado que afecten directamente los intereses colectivos de la comunidad, deberán primar la integridad y respeto de cada uno de sus integrantes. Nuestra Constitución Política refiere la propiedad comunal de las tierras de los campesinos, por ende son capaces de decidir sobre el futuro de las mismas para beneficio común y no perjudicar el entorno ancestral.

En conclusión, el derecho a la consulta previa protegido por nuestra Constitución Política (Congreso de la República, 2011, 1993), así como por el Convenio 169 de la OIT (Organi-

12 A. Peña, "Las comunidades campesinas y nativas en la Constitución Política del Perú: un análisis exegético del Artículo 89 de la Constitución”. Revista Derecho \& Sociedad: Asociación Civil de la PUCP, (s. f.): 26. 
zación Internacional del Trabajo, 1989), y la Declaración de las Naciones Unidas sobre Derechos de los Pueblos Indígenas (Naciones Unidas, 2007), no se viene aplicando de manera correcta, generando constantes afectaciones a territorios indígenas y campesinos por parte de empresa mineras y petroleras. Asimismo, el derecho a ser consultado constituye una exigencia constitucional porque versa sobre derechos colectivos integracionistas.

\section{EL DERECHO DE CONSULTA PREVIA EN COMUNIDADES CAMPESINAS}

Para el mayor detalle de esta temática, es indispensable asumir, en un principio, que el derecho a la consulta previa está orientado en la protección de intereses colectivos. En ese sentido, la vulneración a este derecho constitucional constituye el incumplimiento de normas que salvaguardan el acceso a la consulta y el respeto de sus características ancestrales. En definitiva, el derecho a la consulta es un derecho fundamental, cuya finalidad es preservar y proteger el origen de las comunidades campesinas, teniendo en cuenta que estas se encuentran en constante evolución y cada vez van adquiriendo mejores reconocimientos por organismos internacionales protectores del medio ambiente y de los recursos naturales.

Rivadeneira ${ }^{13}$ señala que los pueblos indígenas han luchado por lograr que se reconozca la necesidad de contar con su consentimiento previo, libre e informado antes de tomar una medida o realizar un proyecto que pueda afectarlos para que no solo sean consultados antes de la adopción de dicha procedimiento por el cual se socializan algunas decisiones ya tomadas sobre una medida específica, independientemente de las opiniones que puedan tener las comunidades afectadas al respecto, sino que debe entenderse y desarrollarse como un verdadero mecanismo de consulta, participación y conciliación, cuyo objetivo sea lograr un acuerdo entre las partes.

Es por ello que, la Ley de Consulta Previa No 29785 (Congreso de la Republica. 2011), busca establecer en principio que las comunidades indígenas sean libres de decidir sobre sus prioridades. Esto es, que el Estado no puede desarrollar proyectos de inversión en territorios indígenas sin antes haber consultado a la comunidad en donde se pretende realizar dicha actividad extractiva. Este proceso consultivo debe plantearse de buena fe. Es decir, las decisiones y acuerdos tomados entre representantes de la comunidad y el Estado primarán sobre cualquier tipo de interés particular. En tal sentido, este derecho de igual manera debe ser aplicado para las Comunidades Campesinasy la responsabilidad será atribuida al Estado si permite o concesiona parte de territorios para desarrollar actividades de explotación de recursos naturales afectando los intereses y propiedad colectiva con lo que cuentan los campesinos.

13 A. Rivadeneira, "El derecho a la consulta previa de los pueblos indígenas: apuntes sobre su tratamiento en el derecho comparado y nacional", acceso el 28 de agosto de 2018, http://www.derecho.usmp.edu.pe/itaest2010/Articulos_estudiantiles/12-2010_articulo_derecho_a_la_consulta_previa_26.12.10.pdf 
Los presupuestos para entender, analizar y aplicar el derecho a la consulta se basan en normas internacionales (pactos y convenios) y nacionales (Constitución Política y leyes especiales, etc.) encargadas de velar por la protección y conservación de costumbres y de la identidad cultural que posee cada comunidad indígena. Lo que se busca, en concreto, es establecer un acuerdo entre Estado y pueblo indígena a través del diálogo y con la utilización de medios idóneos que garanticen la inclusión de estas comunidades en las decisiones estatales.

El contenido del derecho de consulta es importante porque garantiza la subsistencia de derechos fundamentales atribuidos a comunidades indígenas y campesinas. La doctrina mayoritaria respecto a los derechos fundamentales desarrolla dos teorías basadas en su contenido esencial. La teoría absoluta, que en principio busca una limitación del núcleo de los derechos fundamentales dentro de dos esferas específicas: parte externa o accesoria y parte interna o núcleo fijo. En la primera, se pueden establecer restricciones y limitaciones que a la vez son necesarias y justificadas para salvaguardar otros derechos y, en la segunda, entendida como el ámbito normativo de los derechos fundamentales como un núcleo fijo e inmutable. Es decir, son intocables ante cualquier tipo de vulneración. Por otro lado, la teoría relativa, se fundamenta en que los derechos fundamentales se atienden en base a casos y ponderamiento de los perjuicios y beneficios que se produzcan en él, tanto para el derecho intervenido como para el bien protegido. Dicho de otro modo, este contenido constituye un elemento discutible basado en el ejercicio atribuido por el sujeto y una situación jurídicamente protegida.

El papel interventor de cada una de las comunidades campesinas constituye una representación institucional en todo nuestro territorio. Desde el punto de vista social, las comunidades campesinas son unidades cuya finalidad es buscar la propiedad colectiva de las tierras y que estas sean declaradas como tales para los comuneros. Asimismo, las comunidades campesinas son organizaciones que han ido evolucionando en el trascurso del tiempo. Es decir, estas organizaciones han ido creciendo y aportando significativamente la concentración de individuos en diferentes zonas de nuestro país. Esto es, el incremento de familias y de superficie ha hecho que impacten en la estructura política nacional.

Después de haber esbozado algunos conceptos generales, es pertinente entrar al análisis y aclarar la postura de por qué se debe aplicar la consulta previa a las comunidades campesinas. Si bien existe una ley que versa específicamente sobre comunidades campesinas, en ella no se señala la forma y ante qué situaciones se debe de aplicar la consulta previa. Por ello, debe modificarse la citada Ley, a fin de que se aplique la consulta previa como un derecho constitucional y una exigencia supranacional. Es decir, la obligación del Estado de aplicarlo cada vez que se afecten intereses colectivos de los comuneros.

En primer lugar, la aplicación de este derecho debe fundamentarse en: 1) el territorio campesino e indígena son controlados y determinados por ellos mismos, 2) las actividades de 
supervivencia lo realizan de acuerdo a sus necesidades, y 3) poseen características culturales propias (costumbres, tradiciones, etnias, lenguas, etc.). Por ello, dado el grado de afectación por parte de aquellas decisiones del Estado o actividades realizadas por empresas extractivas, ponen en evidencia el rompimiento de barreras de protección del derecho constitucional en aras de proteger el entorno cultural y a vivir y desarrollarse en un ambiente sano y sin contaminación para el desarrollo de la vida.

En segundo lugar, es menester recalcar que de llevarse a cabo un proceso consultivo en donde se haya tomado en consideración la voluntad y decisión de la comunidad en donde se desarrolló dicho proceso, el Estado debe cumplir un rol fiscalizador porque el simple hecho de consultar no quiere decir que la empresa concesionada desarrolle actividades de contaminación, porque ello acarrearía enormes responsabilidades en el sentido de que tendrá que, de una u otra manera, reparar el dańo ocasionado como lo sucedido con el derrame de mercurio por la minera Yanacocha hace más de una década.

En tercer lugar, las decisiones legislativas y administrativas así como las actividades de exploración y extracción que se tomen sin tener en cuenta la voluntad de los campesinos lesionan y pone el peligro derechos constitucionales reconocidos, no solamente en el país sino en el ámbito internacional. De tal manera que la realización de ciertas conductas debe ser considerada suficiente para que Estado, y que sin necesidad de demostrar todo lo contrario, pueda aplicar el proceso de consulta previa.

Por último, el derecho de consulta previa debe reconocerse y aplicarse legalmente a las comunidades campesinas, en razón de que los espacios y territorios en donde los comuneros desarrollan sus actividades agropecuarias en beneficio de la comunidad y para satisfacer necesidades se supervivencia son protegidos en principio por nuestra Constitución Política y leyes especiales relacionados con la consulta previa. Además, el Gobierno debe promover y fortalecer aquellas políticas enfocadas en aquellos organismos públicos encargados de conducir un proceso consultivo.

\section{CONCLUSIONES}

1. En definitiva, los diferentes tratados y convenios internaciones se caracterizan por su notable aportación en cuanto a la protección de los derechos con que cuentan los pueblos indígenas y por la existencia de organismos internacionales encargados de velar estas afectaciones a sus derechos humanos. Además, el tema de consulta previa actualmente ya traspasó fronteras; por ende, es considerado un asunto especializado dentro del ámbito jurídico, político y social.

2. El Estado es el único obligado a implementar el proceso de consulta previa, y lo hace a través de organismos descentralizados como el Congreso de la República, los Ministe- 
rios, los Gobiernos Regionales y Municipalidades, etc. Dicho esto, las empresas deben ceñirse a criterios en los derechos de las comunidades locales y no a la negociación con los pueblos, y siendo fundamental el acceso a criterios económicos en su espacio territorial, deben realizar actividades de responsabilidad social para crear un ambiente de diálogo y relaciones con los indígenas.

3. El derecho a la consulta previa protegido por nuestra Constitución Política así como por el Convenio 169 de la OIT y la Declaración de las Naciones Unidas sobre Derechos de los Pueblos Indígenas no se viene aplicando de manera correcta, pese a las constantes afectaciones a territorios indígenas y campesinos por parte de empresas mineras y petroleras. Asimismo, el derecho a ser consultado constituye una exigencia constitucional porque versa sobre derechos colectivos integracionistas.

4. La consulta debe realizarse incluyendo iniciativas de desarrollo para las comunidades campesinas y pueblos indígenas. Esto es, el desarrollo de sus propias instituciones y respeto de su entorno cultural. El Estado tiene la obligación de consultar si prevé que en un futuro pueden generarse conflictos sociales entre el Estado y las organizaciones indígenas.

\section{REFERENCIAS}

- Congreso de la República, Ley N²8237. Acceso el 17 de setiembre de 2018. https:// www.tc.gob.pe/tc/private/adjuntos/institucional/normatividad/codigo_procesal.pdf

- Declaración de las Naciones Unidas sobre los Derechos de los Pueblos Indígenas (Oficina Regional para América Latina y el Caribe, 2007). Acceso el 28 de agosto de 2018. http:// www.ilo.org/wcmsp5/groups/public/---americas/---ro-lima/documents/publication/ wcms_345065.pdf

- Peña, A. "Las comunidades campesinas y nativas en la Constitución Política del Perú: un análisis exegético del Artículo 89० de la Constitución”. Revista Derecho \& Sociedad: Asociación Civil de la PUCP, (s. f.).

- Rivadeneira, A. "El derecho a la consulta previa de los pueblos indígenas: apuntes sobre su tratamiento en el derecho comparado y nacional". Acceso el 28 de agosto de 2018. http:// www.derecho.usmp.edu.pe/itaest2010/Articulos_estudiantiles/12-2010_articulo_derecho_a_la_consulta_previa_26.12.10.pdf 
- Tribunal Constitucional. Jurisprudencia, 2005. Acceso el 15 de setiembre. http://www. tc.gob.pe/jurisprudencia/2006/00025-2005-AI\%2000026-2005-AI\%20Admisibilidad. html

- Tribunal Constitucional. Jurisprudencia, 2009. Acceso el 18 de setiembre de 2018. https://www.tc.gob.pe/jurisprudencia/2010/00022-2009-AI.html

- Tribunal Constitucional. Jurisprudencia, 2011. Acceso el 18 de setiembre de 2018, http:// www.tc.gob.pe/jurisprudencia/2012/01126-2011-HC.html

- Valle, J. "Comisión de Constitución elaborará tercer dictamen sobre Ley de Consulta", 2010. https://www.servindi.org/actualidad/25629

RECIBIDO: $19 / 09 / 2018$

APROBADO: 27/10/2018 